\title{
ECN Pressure Test
}

\subsection{4-EN-319}

\author{
July 18, 1991 \\ K. Dixon
}




\section{ECN PRESSURE TEST}

This note describes: the rationale for the test pressure of the inner ECN cryostat vessel, the equipment to be used in this test, the test procedure, the status of the vessel prior to the test, the actual test results, and a schematic diagram of the testing set up and the pressure testing permit.

\section{Test Pressure}

The ECN inner vessel was pneumatically pressure tested to $33 \mathrm{psig}$ at the fabricator, Process Engineering in Plaistow, New Hampshire. The test pressure was determined as follows:

Test Pressure $=(1.25 \times$ MAWP $)+14.7$ psig (full vacuum)

$$
\begin{aligned}
& =(1.25 \times 15 \mathrm{psig})+14.7 \mathrm{psig} \\
& =33.4 \text { or } 33 \mathrm{psig}
\end{aligned}
$$

Removal and replacement of the heads and the installation of the nozzle extensions ( 4 signal boxes, 2 high voltage boxes, 1 instrumentation box, 1 cold valve, and other appurtenances) are considered justification to do an additional pressure test on the completed calorimeter. The removal and subsequent welding of the heads, the beam and bypass tubes can be classified as "routine repairs"; ie, no additional pressure test is required by the rules of the National Board Inspection Code unless the inspector specifically requests it.

The pressure testing performed at the vessel manufacturer did not take into account the "head" or additional pressure due to the weight of the liquid argon. A possible solution is to fill the vessel with liquid for the test, and install the vacuum jacket before the pressure test. Unfortunately, the vessel can not be filled with water without compromising the integrity of the modules within. Nor can it be filled with potentially dangerous liquid argon since the integrity of the vessel has not been established prior to this testing. Also, the vacuum vessel can not reasonably be welded into 
place to provide the vacuum loading (or insulation) if the final leak check is to follow the pressure test. This test sequence is accepted practice for obvious reasons.

The usual accommodation which Process Engineering elected to do, is to relinquish the head pressure requirement. This works well on high pressure vessels, those with small heights, and/or those with low density liquids because the head pressure is a small fraction of the maximum load test pressure. The resolution for low pressure, tall, and high density liquid vessels (our situation) is more difficult, and not as obvious. The compromise proposed in this case, which was the same for the CC cryostat, is to test the entire vessel to the maximum pressure that it will experience which will be at the bottom. Therefore, the proposed test pressure is

$$
[15.0(\text { MAWP })+14.7(\text { Full Vacuum })+10.0(\text { head })] \mathrm{psig}=39.7 \text { or } 40 \mathrm{psig} \text {. }
$$

Since the multiple extensions emerge from the vacuum head near the top of the vessel of the vessel, they will never be exposed to an operational pressure of more than 15 psig. Although the nozzle extensions and their parts will be exposed to $267 \%$ of their design pressure by testing the vessel to the above derived test pressure, these extensions and parts have all been previously hydrostatically tested successfully to 48 psig.

\section{Equipment Setup/Preparations}

The pressurizing source will be a 160 liter (nom), high pressure ( $250 \mathrm{psig}$ ), argon dewar connected to an extruded aluminum fin vaporizer (see schematic). Pressure will be controlled by a single stage, high flow regulator (Linde Model SG3882) which will be located safely away from the cryostat. A relief valve set just above the maximum test pressure will be located on a tap at the top of the vessel and two relief valves set below the maximum design pressures of the piping will be located on each side of the regulator. Two 0-100 psig compound pressure indicators will be used: one connected directly to the vessel volume at the top tap, and the other located downstream of the pressure regulator. In addition, there will be a pressure transmitter with a readout and trending information available in 
the Cryo Control Room.

A 2 micron filter will trap UO particles from the cryostat during the blowdown process. The element will be further analyzed after the test and the results given to $\mathrm{RD} / \mathrm{Safety}$.

The testing will be performed after normal working hours either during the evening or on a weekend. No non-testing personnel will be allowed west of the counting or clean rooms in the high bay area and pit. The control of the pressurizing source will be located in the pit or another nonexposed area. The test should take about two hours to perform.

All arrangements with Standard Boiler and their designated Code inspector shall be made a couple of days prior to the testing. The inspector must be present to witness the testing.

\section{Testing Procedure}

1. Ensure that: the piping has been recently cleaned and is in accordance with the attached piping schematic, relief valve settings have been recently verified, the 160 liter dewar is at least $3 / 4$ full, all pumpouts (including the PI-equipped beam tube ones) and ports other than the fill/drain line have been capped and piping components not compatible with the maximum test pressure removed.

2. The video monitor should be transmitting the image of the pressure indicator on top of the cryostat to a monitor located safely away from the cryostat. The person responsible for starting/stopping the pressurization process should have access to this monitor either directly or by means of radio transmitters.

3. Make an announcement over the building PA system to instruct all personnel not associated with the testing to leave the high bay area/pit west of the counting and clean rooms. Place signs suspended from ropes across all entryways to this area warning people to keep away during the testing. 
4. Make sure that the Code inspector and a witness from $R D /$ Safety is present.

5. Pressurize the vessel to 20 psig as read on the indicator mounted on the top of the vessel. Hold at this pressure for ten minutes and listen for any leaks and notice if there is any drop in pressure. Leaks on compression or VCO type connectors can be fixed by tightening the connectors; however, those found on large flanges should be fixed only after entirely depressurizing the vessel. Any anomalies should be recorded in the Cryo Logbook.

6. ALL personnel should leave the high bay areas exposed to the testing at this time. Proceed to increase the pressure in the vessel at a rate no greater than 4 psi/10 minutes. This rate can be checked on the PLC historical trending. Continue to pressurize until the maximum test pressure of 40 psig is reached and hold at this pressure for 10 minutes. Again note any drop in pressure but do not attempt to locate leaks at this point.

7. Should any sign of vessel failure or distortion be observed, then terminate the test immediately by bleeding down the pressure entirely through the filter. A final disposition for the vessel will be arranged by the appropriate authorities.

8. Depressurize the vessel to 30 psig through the filter and inspect the circumferential welds of the vessel and those around the beam and bypass tubes with a soap solution. The soap testing shall be augmented with a 30 minute pressure drop test. The beam tube bellows assembly pumpout indicators should be checked for any presence of pressure buildup.

9. Upon successful completion of the test, then reduce the pressure to atmospheric pressure and secure the pressure source. The warning signs may be removed and make an announcement to building personnel stating that "the west high bay area is accessible". Obtain signatures from the appropriate personnel on the test permit. 


\section{Vessel Status Prior to Testing}

The inner vessel heads including the argon excluder, bypass and beam tubes had just been welded into place. The vacuum heads were not on at this time but the vacuum shell was on covering the piping penetrating into the inner vessel. Signal boxes with all feed through boards, the instrumentation box, and high voltage boxes were all installed with their pump outs capped. All 1/4" instrumentation lines were terminated at their respective shutoff valves. The pumpout volumes between the bypass beam tube bellows were terminated with pressure indicators. The vessel had its welds taped and leak checked to a sensitivity of about $8 \mathrm{E}-6$ atm$\mathrm{cc} / \mathrm{s}$ He which is well within the criterion for this vessel.

All vacuum piping and instrumentation used for pumping down the inner vessel were removed as were the 4" VRC gate valve isolating the blower cart, and both the rupture disk and relief valve were also removed and replaced with blind flanges before pressurizing due to their pressure limitations. Stresses in plates used as blind flanges were checked using Code calcualtions. Before the CC pressure test, KF50 blanks and clamps were hydrostatically pressure tested to $150 \%$ of the maximum test pressure, 60 psig.

The Code inspector and Research Division Safety had all given their approval to the test pressure and procedure prior to filling the vessel with argon.

\section{Test Results}

The test, performed in the evening of July 17,1991 , was a major success. Based on a neglible pressure drop indicated on the pressure gages (1/4 psi), the vessel appeared to be structurally sound throughout the duration of the test (approx. $1.5 \mathrm{hrs}$.). No pressure increases were observed on the indicators looking at the beam tube bellows volumes. There was no indication of bubbles form the soap test on the welds and most of the fittings that were checked. 
There were some slight deviations in the actual procedure used. The UO filter was removed after the vessel had bled down to about 18 psig in order to speed up that aspect of the test. The rationale was that the higher velocity gas had already passed through at the higher pressures and there was no visible traces of the black uo particles. The rate of 4 psi/10 minutes seemed incredibly slow and of ten that time was reduced to just over half that rate. The testing personnel was allowed to stay in the pit throughout the duration of the test; this was a slight relaxation of the rules.

After the test was completed, the inspector from The Hartford Steam Boiler Inspection and Insurance Co. and the Research Divison Safety Officer signed all of required documentation. 


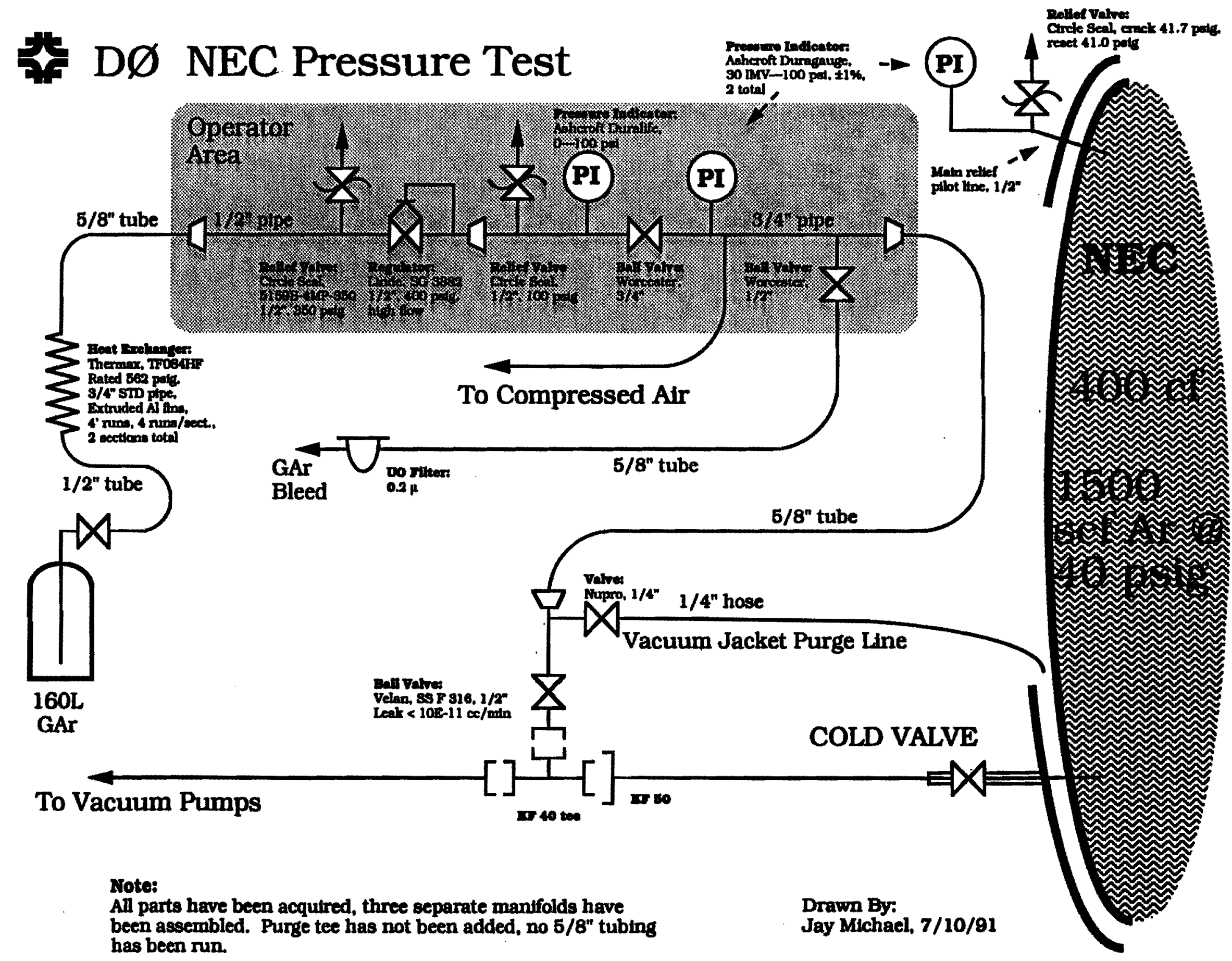
been assembled. Purge tee has not been added, no $5 / 8^{\prime \prime}$ tubing Jay Michael, 7/10/91 
Fermilab

EXHIBIT B

Pressure Testing Permit*

Type of Test: $\square$ Hydrostatic

Test Pressure: $4 \mathrm{C}^{\prime}$ sig Maximum Allowable Working Pressure: $15+F$ psia Items to be rested: ECN cryostat w/ electrical / Leathery boxes articled ti the tip of the vessel.

Location of Test: North Sideulatk/DAB Date and Time:

Hazards Involved: Large built up frees dine ti pressures over large surface areas, possible head separation, strapnet, ifc. Cryogens used to pres sanitize lesser.

Safety precautions Taken: (1). high bay area liacuated aside from test perscumelin pit protected by concrete wall. Relief calves on piping.

Special conditions or Requirements: C le remote camera te monitor pressure, The vacuum hes as will mat be atfueled at thus time.

Test Coordinator:

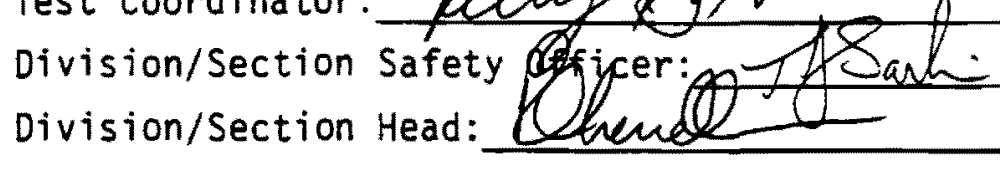
Results:

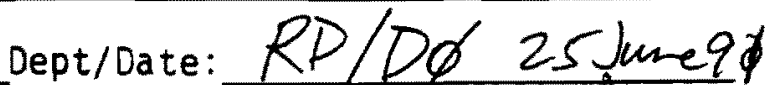

Dept/Date: RDES/H 25 Un eq/

Dept/Date: RDO fane 26,91

Witness:

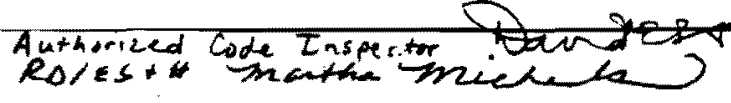
Dept/Date: $17 \mathrm{Juh} 97$

(Safety Officer or Designed)

*Must be signed by division/section safety officer and division head prior to conducting test. It is the responsibility of the test coordinator to obtain signatures. 